\title{
Study of propofol-thiopental mixture for induction of general anesthesia in xylazine premedicated Donkeys
}

\author{
O.A. Bader \\ L.M. AL-kattan \\ Coll. of Vet. Med./ Unive. of Mosul
}

\begin{abstract}
The current study was conducted to evaluate the anesthetic quality produced by Propofol-Thiopental mixture (P-T) in six donkeys premedicated with Xylazine (X), (1.1 $\mathrm{mg} / \mathrm{kg}$ IV). The intravenous dose schedule for P-T mixture was 1,2 and $4 \mathrm{mg} / \mathrm{kg}$ of Propofol with $5 \mathrm{mg} / \mathrm{kg}$ of Thiopental Sodium, respectively. Each donkey was anesthetized three times with each dose of P-T, five minutes after $\mathrm{X}$ administration in random order at one week intervals. The anesthetic parameters induction, duration of anesthesia, time to sedation and recovery times, cardiovascular parameters, respiratory parameters and incidence of sideeffects were qualitatively and quantitatively assessed.The results of the present study revealed presence of wide range of differences in the quality of anesthesia between the three doses of P-T mixture. The high dose of P-T mixture $(4 \mathrm{mg} / \mathrm{kg}+5 \mathrm{mg} / \mathrm{kg})$ produced an ultra induction

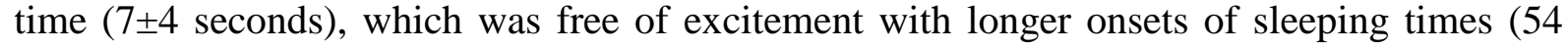
min). But, times to regain sternal and standing positions were longer with this dose. While, the low dose $(1 \mathrm{mg} / \mathrm{kg}+5 \mathrm{mg} / \mathrm{kg})$ failed to produce narcosis. On the other hand, the (2 $\mathrm{mg} / \mathrm{kg}+5 \mathrm{mg} / \mathrm{kg}$ ) of P-T, produced smooth induction (17.5 \pm 3 seconds) with sufficient tracheal intubations. Time to narcosis was shorter than that produced by the higher dose (animal still

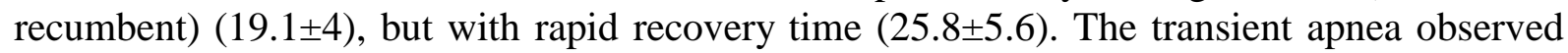
in this study which was usually followed by administration of P-T mixture, was shorter ( $37.8 \pm 18 \mathrm{sec}$.) with the medium dose $(2 \mathrm{mg} / \mathrm{kg}+5 \mathrm{mg} / \mathrm{kg})$, compared to that with the higher dose.It could be concluded that P-T mixture $(2 \mathrm{mg} / \mathrm{kg}+5 \mathrm{mg} / \mathrm{kg})$, is an excellent anesthetic protocol for induction of general anesthesia in donkeys. It is the first record for the use of this mixture for general anesthesia in this animal.
\end{abstract}

Key words: General anesthesia, Donkey, Propofol-Thiopental mixture.

\section{Introduction}

Donkeys are desert adapted animals, who survive where horses cannot (1). Behavioral differences are also seen in their responses to injections, twitches, leading, and other common procedures related to anesthesia. By nature, their disposition is quite sedate, therefore recovery from anesthesia and surgery is almost always smooth and without excitement (2). Thiopentone is a highly lipid -soluble weak organic acid, highly irritant if the concentration is greater than $2.5 \%$. It's act as an induction agent in all species, it currently administrated to induce anesthesia by given one-half and tow-third of the calculated dose, apnea is common on induction of anesthesia after thiopentone administration

Thiopentone produce rapid and smooth induction with rapid loss of consciousness because it cross the blood brain barrier rapidly but it has poor analgesia. Recovery from thiopental is long because it is depends upon metabolism of the drug rather than redistribution (4, 5).Propofol (Diprivan, ICI) is a rapid acting ultra short, non barbiturate drug and relatively non cumulative IV anesthetics (6).It is an alkyl phenol hypnotic drug and it has been investigated as an intravenous anesthetic material in dogs and cats in the United Kingdom (7). The drug was reported to be rapidly metabolized agent characterized by a virtual lack of any cumulative effect and by rapid recovery after its administration in bolus doses or by continuous infusion. in equine, and it was found to have a desirable pharmacokinetic profile in horses, as rapid onset of action non cumulative i.v agent as described. Many studies of the combination of propofol with alpha 2-agonist and opioid were 
investigated (8), on other hand propofol has lack analgesic effect (9) and the most side effects are pain on injection. This pain can be resolved by pretreatment with lidocaine (10). Xylazine is a $\alpha 2$ agonist produce CNS depression by stimulating both presynaptic and postsynaptic $\alpha 2-$ adrenoceptors in CNS and peripherally nerves. It produce prolong sedation,

\section{Materials and Methods}

Six adult male donkeys were included current study, the experiment animals ranged in aged 2-3 years and weighted from 100-135 kg from local breed. Food was withheld for $12 \mathrm{hr}$ before the experiment, but water was freely accessible. There are fifteen days intervals between each treatment. The experiment design as the followings:

\section{First series (Dose setting):}

Six adult donkeys prepared routinely for obtain optimal dose of such mixture P$\mathrm{T}$ to emphasis the ideal dose with good qualities of anesthesia and rapid induction with smooth recovery and minimal side effect. Intravenous propofol (Diprivan, ICI - Zeneca Pharmaceuticals) supplied as $10 \mathrm{mg} / \mathrm{ml}$ of white, oil - in - water emulsion in a 20-ml ampoule for intravenous injection inject at a dose of $1 \mathrm{mg} / \mathrm{kg}$ B.wt mixed with thiopentone $5 \mathrm{mg} / \mathrm{kg}$ B.wt after $5 \mathrm{~min}$ of giving i.v Xylazine at the dose of $1.1 \mathrm{mg} \mathrm{kg}$ B.wt. At this group the following parameters were determined: Onset of analgesia, time to sedation, duration of recovery time and degree of analgesia which was measured by all reflexes as swallowing, balbabral reflex, respiratory rate and heart rate.

\section{Third series:}

muscle relaxation and analgesia (11). The aim of this study was to compare the effects of three anesthetic doses of thiopental - propofol in xylazine premedicated donkeys to produce good qualitative and quantitative anesthetic properties and to estimate which anesthetic regime provided satisfactory results when used in donkeys.

\section{Second series:}

Six adult donkeys prepared routinely after 15 days interval of first treatment and mixture of P-T administrated at a dose of Propofol $2 \mathrm{mg} / \mathrm{kg}$ B.wt + Thiopentone $5 \mathrm{mg}$ $/ \mathrm{kg}$ B.wt after $5 \mathrm{~min}$ of giving i.v Xylazine at the dose of $1.1 \mathrm{mg} \mathrm{kg} \mathrm{B.wt}$ for induce good quality of anesthesia with minimal side effect the, following parameters was monitored: Time to induction, time to sedation, quality of anesthesia and analgesia, duration of apnea, the possibility of intubations (the endotracheal tube was removed once swallowing reflex returned) and quality and time to recovery (quality of recovery determined by monitoring the plane of anesthesia which was determined by the assessment to the degree of muscle relaxation and incidence of side effect).

After interval of one week same animals as same manner of G1 and G2 mixture at the dose of Propofol $4 \mathrm{mg} / \mathrm{kg}$ B.wt +Thiopentone $5 \mathrm{mg} / \mathrm{kg}$ B.wt after 5 min of giving i.v Xylazine at the dose of $1.1 \mathrm{mg} \mathrm{kg} \mathrm{B.wt}$, the parameters taken as in G1and G2 and comparisons between three groups were made.

\section{Results}

Anesthesia with thiopentonepropofol characterized by good muscle relaxation and abolishment of reflexes. The results of this study shown that the mixture of (P-T) induced good and smooth anesthesia and free from exciting induction with smooth recovery at the dose of $\mathrm{P} 2$ $\mathrm{mg} / \mathrm{kg} \mathrm{B.wt}+\mathrm{T} 5 \mathrm{mg} / \mathrm{kg}$ B.wt . All operative animals were easy intubated between the first and second attempted. The time of induction was $(17.5 \pm 3 \mathrm{sec}$.) whereas the anesthesia lasted at $(19.1 \pm 4$ min) (table 1).The treated donkeys exhibited some systemic effects of mixture. These signs included good deal of sedation and low head carriage, excessive salivation with drooling, these signs were notice on an average about two minute after intravenous injection and persisted for the 25 minute, the onset of sedation was (2.1 \pm 0.6 minute) of treatment with this mixture. Such signs were observed with 
other two groups in different degree and exhibition, in G1 time to sedation was $(1.5 \pm 0.7 \mathrm{~min})$ while in $\mathrm{G} 3$ was $(3 \pm 0.6$ minute) (table 1).In third group $(4 \mathrm{mg} / \mathrm{kg}$ B.wt +Thiopentone $5 \mathrm{mg} / \mathrm{kg}$ B.wt) the induction was slow and the recovery was stormy and rough as contrast with first and second group, the mean time of induction was longer $(50 \pm 6.2 \mathrm{sec})$.At induction apnea lasting up to 92 seconds, it was the most prevalent side-effect, but did not require any form of assisted ventilation. As contrast this observation recorded minimally in first group $(19 \pm 8.6$ sec.) and in second group (37.8 $\pm 18 \mathrm{sec}$.) (table 2).At time zero the values of RR were obtained immediately after induction of anesthesia with propofol, the decreases in RR obtained after 5 min but retrain to the normal level pre and post induction of anesthesia (figure 1) without significant differences in three groups' .at the different periods of monitoring. There are significant differences between G1, G2 and G3 in Heart rate at the $\mathrm{P}=0.001$ (figure 2).

Table 1: Represent the anesthetic properties of $(\mathrm{P}-\mathrm{T})$ a comparison between three different doses.

\begin{tabular}{|c|c|c|c|c|}
\hline & $\begin{array}{c}\text { Induction } \\
\text { time/ } \\
\text { Sec. }\end{array}$ & $\begin{array}{c}\text { Onset of } \\
\text { sedation/ } \\
\text { Min. }\end{array}$ & $\begin{array}{c}\text { Time of sternal } \\
\text { recumbence/ } \\
\text { Min. }\end{array}$ & $\begin{array}{c}\text { Duration of } \\
\text { recovery/ } \\
\text { Min. }\end{array}$ \\
\hline $\begin{array}{c}\text { Propofol 1mg } \\
+ \\
\text { Thiopentone } \\
5 \mathrm{mg}\end{array}$ & $8.3 \pm 0.9$ & $1.5 \pm 0.7$ & $23.1 \pm 5.2$ & $16.3 \pm 1.1$ \\
\hline $\begin{array}{c}\text { Propofol 2mg } \\
+ \\
\text { Thiopentone } \\
5 \mathrm{mg}\end{array}$ & $17.5 \pm 3$ & $2.1 \pm 0.6$ & $19.1 \pm 4$ & $25.8 \pm 5.6$ \\
\hline $\begin{array}{c}\text { Propofol 4mg } \\
+\end{array}$ \\
$\begin{array}{c}\text { Thiopentone } \\
5 \mathrm{mg}\end{array}$
\end{tabular}

Table 2: Represent the reflexes response of (P-T) a comparison between three Different doses.

\begin{tabular}{|c|c|c|c|}
\hline & $\begin{array}{c}\text { Time of absence } \\
\text { of balbabral } \\
\text { reflex / Min. }\end{array}$ & $\begin{array}{c}\text { Disappearance of } \\
\text { Swallowing } \\
\text { Min. }\end{array}$ & $\begin{array}{c}\text { Duration of Apnea } \\
\text { Sec. }\end{array}$ \\
\hline $\begin{array}{c}\text { Propofol 1mg } \\
+ \\
\text { Thiopentone } \\
5 \mathrm{mg}\end{array}$ & $12 \pm 1.9$ & $12.6 \pm 6.7$ & $19 \pm 8.6$ \\
\hline $\begin{array}{c}\text { Propofol 2mg } \\
+ \\
\text { Thiopentone } \\
5 \mathrm{mg}\end{array}$ & $30 \pm 2.8$ & $20.8 \pm 3.1$ & $37.8 \pm 18$ \\
\hline $\begin{array}{c}\text { Propofol 4mg } \\
+\end{array}$ & $49 \pm 5.5$ & $13.3 \pm 2.3$ & $92 \pm 11$ \\
$\begin{array}{c}\text { Thiopentone } \\
5 \mathrm{mg}\end{array}$ & & & \\
\hline
\end{tabular}




\section{Respiratory rate}

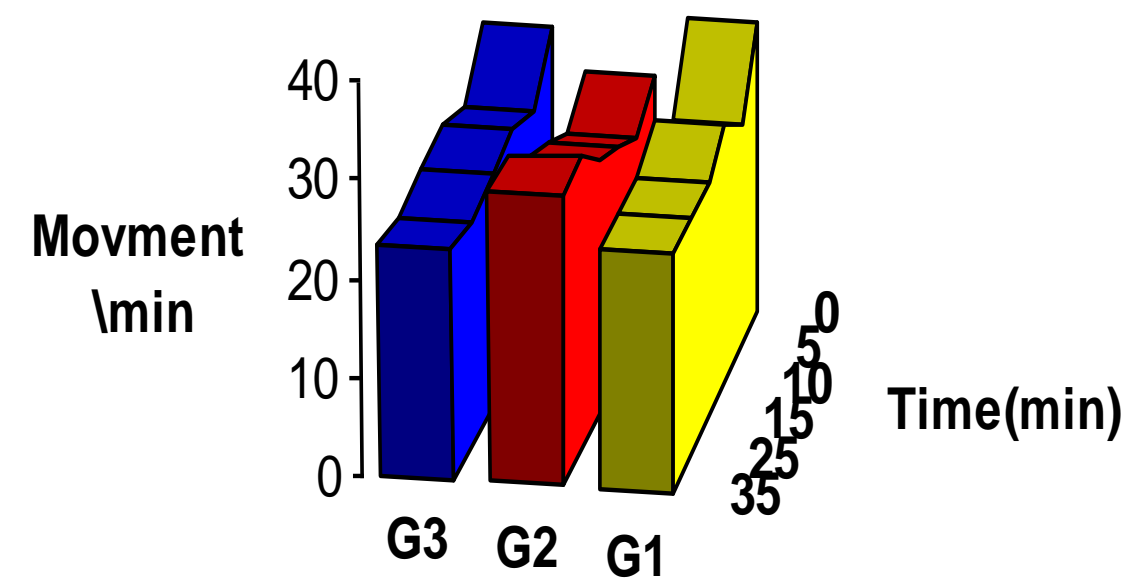

Figure 1: Represent the comparison of respiratory rate between three groups.

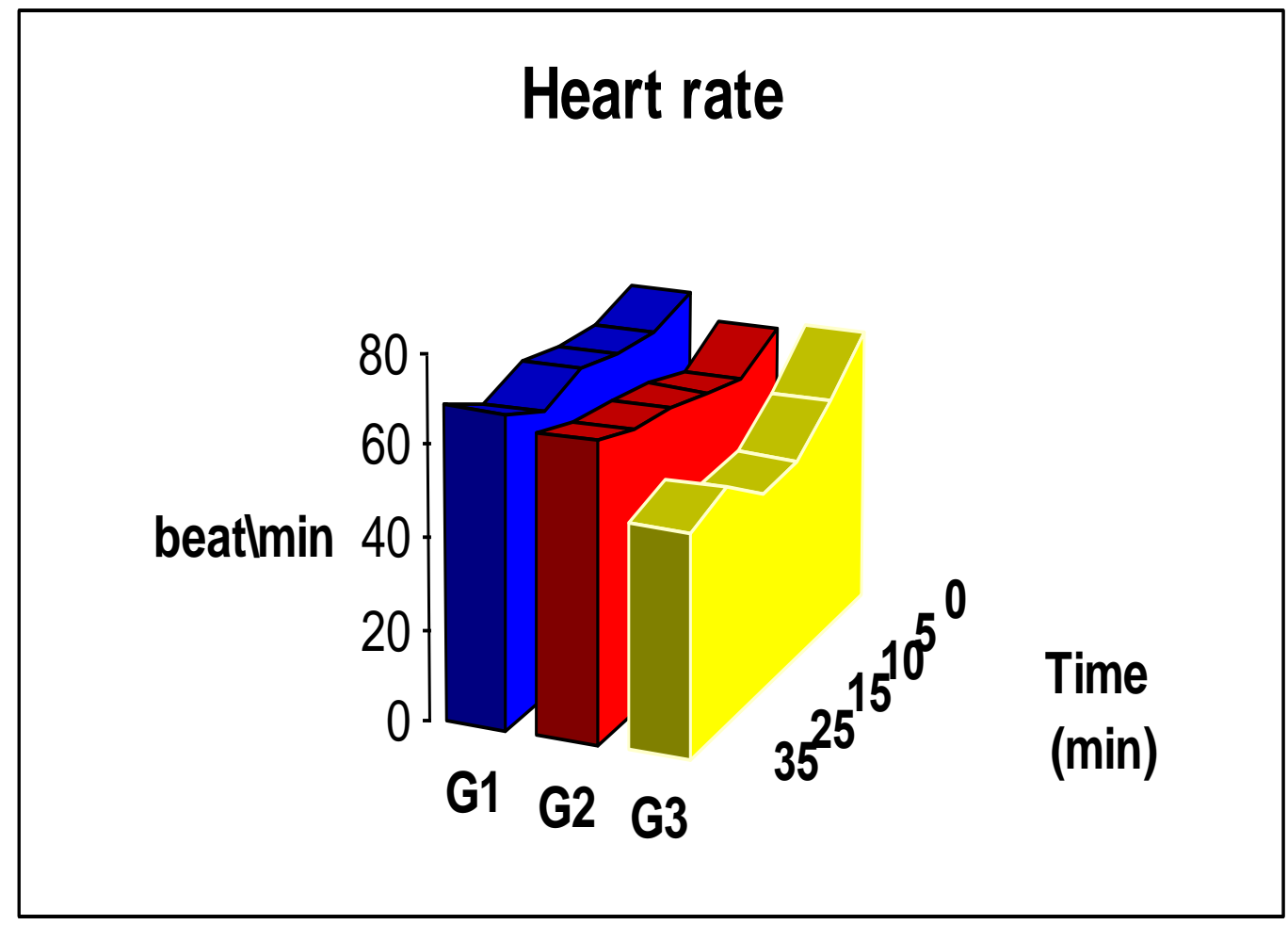

Figure 2: Represent the comparison of Heart rate between three treated groups. 


\section{Discussion}

In current trail, the donkeys were premedicated with $1.1 \mathrm{mg} / \mathrm{kg}$ of xylazine to provide a good quality of analgesic basis for protocol anesthesia for the terms of excitement -free induction with smooth recovery and significant analgesic effect.The milky emulsion appearance of propofol's not prevent flowing of solution and this emulsion easy flow through even a 21 gauge needle without any anaphylactic reaction in all operative donkeys.In current study the induction with propofol characterized with smooth rapid recovery after its intravenous administration. These characteristics clearly relate to the drug pharmacokinetics of propofol $(12,13)$. It has a high lipid solubility results in rapid onset of action as contrast of thiopentone where the recovery was smooth less and rapid, this feature was founded by other worker $(8,14)$.Truly propofol would appear to offer some advantages over the barbiturates including minimal cumulative effects and rapid complete recovery. The only concern for veterinary use of propofol

\section{References}

1. Yousef MK. and Dill DB. (1970). Shifts in body fluids during dehydration in the burro, Equus asinus. J. Appl Physiology. 29:345-349.

2. French J. (2000). The donkey - a small horse? In Proceedings. The donkey: a unique equid. 2-8.

3. Seymour C. and Gleed R. (1999). Manual Small Animal Anesthesia and Analgesia. BSAVA. UK. 8889.

4. Hall LW, Clark KW and Trim CM. (2003). Veterinary Anesthesia $.10^{\text {th }}$ edition W.B. Saunders, Bailliere Tindall, 115-125.

5. Riebold TW, Goble DO and Geiser DR (1982). Large Animal Anesthesia .The IOWA State University Press. AMES, 22-23.

6. Muir, Hubbell JA, Bednarski RM and Skarda RT. (2005).Veterinary Anesthesia $.4^{\text {th }}$ ed. United State .Mosby , ;72-79. relates to its cost and limited shelf life once the ampoule is opened $(4,14)$.In contrast, repeat doses of thiopentone have been shown to have a cumulative effect and prolonged periods of anesthesia (3). One of most side effects after thiopental- propofol anesthesia is transient apnea which was long at the third group. Fortunately, this findings observed for short time hence of no clinical significance $(8,14)$.Admixture of thiopentone with propofol results in an additive hypnotic effect and the improvement recovery of thiopentone because the propofol has a smooth and free excitement recovery. During this study both agents thiopentone and propofol produce similar cardiovascular and respiratory effects through lesser depressed effect on the central nervous system and myocardium (12). The decrease in RR after administration of this mixture possibly by depressing central inspiratory drive and the ventilatory response to arterial carbon dioxide tension $(15,16)$.
7. Hall LW and Chambers JP (1987). A clinical trial of propofol infusion anesthesia in dogs. J. Small Animals. Pract. 28: 623-627.

8. Branson KR. and Gross ME. (1994). Propofol in veterinary medicine. JAVMA 204, 1888-1890.

9. Mathews NS., Taylor TS. and Sullivan JA. (2002).Comparison of three combinations of injectable anesthetics in miniature donkeys Vet Anaesth. Analg; 29:36-42.

10. WWW. Drugs Com. Propofol drugs information professional. Retrieved on 2007-01-02.

11. Greene SA., and Thurmon JC. (1988). Xylazine - A Review of its pharmacology and use in veterinary medicine. J. Vet Pharmaco Therap. 11:295-313.

12. Langley MS. and Keel RC. (1988). Propofol: a review of its pharmacodynamic and pharmacokinetics properties and 
use as an intravenous anesthetic drug. 35: 334-372, 1988.

13. Oku Kazuomi, Yamanaka Takashi, Ashihara Nagatoshi,Kawasaki Ka -zumi, Mizuno Yutaka and Fujinaga Toru (2003). Clinical observations during induction and recovery of xylazine-midazolampropofol anesthesia in horses. J. vet med Sci; 65 (7): 805-808.

14. Watkins SB., Hall LW. and Clarke

\section{KW.(1987). Propofol as an}

intravenous anesthetic agent in dogs. Vet. Rec. 120: 326-29.

15. Goodman NW., Black AM. and Carter JA. (1997). Some ventilatory effects of propofol as sole anesthetic agent. Br. J. Anaesth. 59: -1503 .

16. Tan CH. and Onsiong MK. 1998, Pain on injection of propofol. Anesthesia. 468-476.

\section{دراسة استخدام مزيج البروبوفول- ثايوبنتال في إحداث التخدير العام لحمير

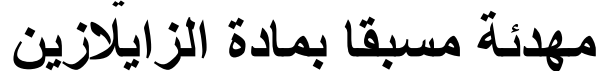

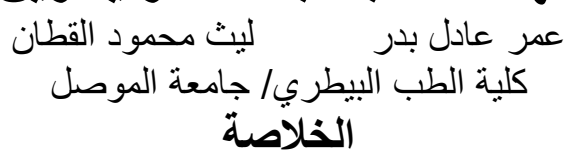

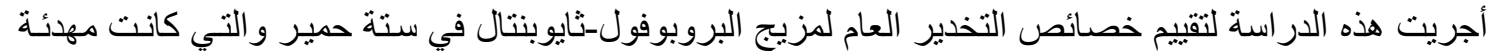

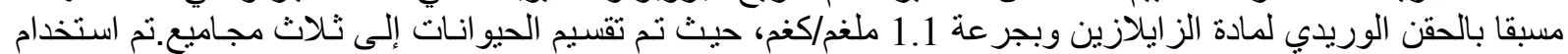

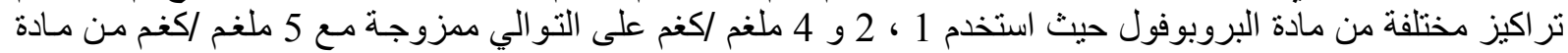

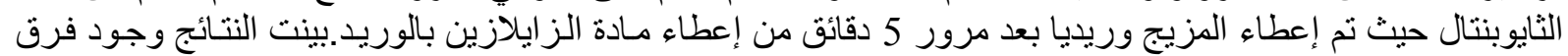

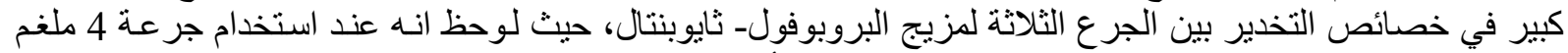

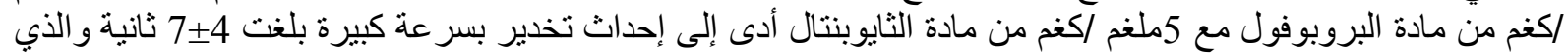

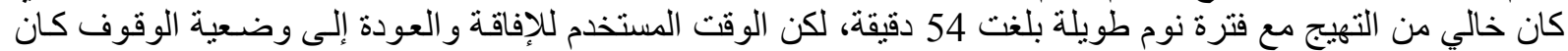

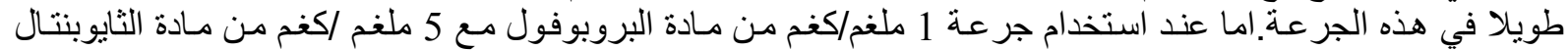

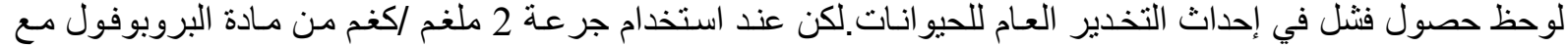

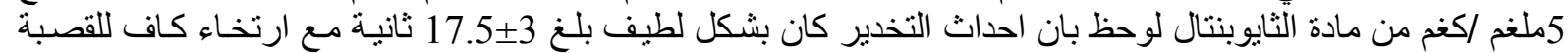

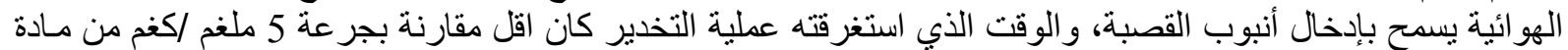

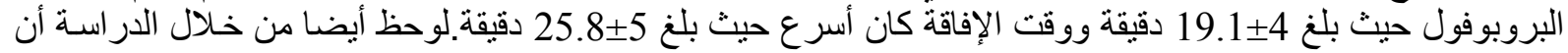

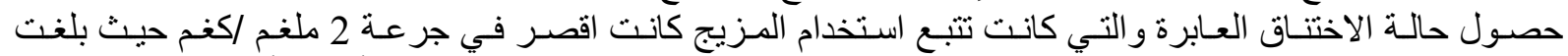

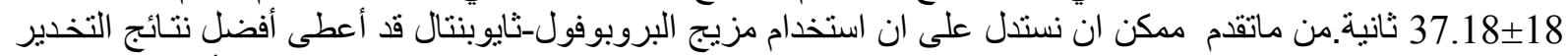

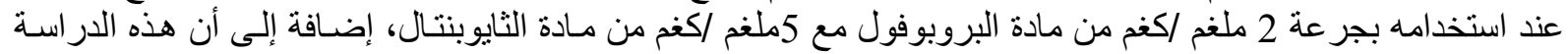
تعتبر الأولى في استخدام المزيج لإحداث التخدير العام في الحيو انات. 